\title{
Research on Control Strategy of SCR Denitration based on Advanced Control Technology
}

\author{
Yang $\mathrm{Ma}^{1, \mathrm{a}^{*}}$, Wei Deng ${ }^{1, \mathrm{~b}}$, Xichang $\operatorname{Han}^{1, \mathrm{c}}$ and Lin Sun ${ }^{1, \mathrm{~d}}$ \\ ${ }^{1}$ Department of automatic control, Shenyang Institute of Engineering, Shenyang 110136, China \\ amayanghc@163.com, ${ }^{b} d w 0310204 @ 126 . c o m,{ }^{c H a n x c @ s i e . e d u . c n, ~}{ }^{d} 845692217$ @qq.com
}

*The corresponding author

\section{Keywords: SCR; Denitration; Optimize; Neural network; Ammonia escape rate}

\begin{abstract}
The principle and technological process of selective catalytic reduction (SCR) were introduced. At present, the domestic SCR denitration closed-loop control strategy is usually designed as a fixed molar ratio control mode. However, this control system only takes into account the efficiency of denitration, and does not consider the change of the concentration of NOx, when the inlet NOx concentration is relatively low, it is easy to make the system over nitrogen and increase the operating costs. This paper puts forward the advanced control technology of SCR denitration control in modern thermal power unit based on neural network learning technology and adaptive control technology, optimizing the control of ammonia flow rate and outlet NOx concentration of SCR. On the basis of taking full account of the denitration efficiency and the ability of denitration of the catalyst, the excessive nitrogen removal caused by the fixed molar ratio control is avoided, and the outlet NOx concentration can be controlled within a reasonable range. And control the ammonia escape rate close to SCR minimum amount of inherent, thereby reducing the consumption of electricity and maintenance plant, improve power generation efficiency.
\end{abstract}

\section{Introduction}

At present, China's annual emissions of nitrogen oxides is second only to the United states. With the rapid development of economy, air pollution has also changed from the coal mine to the mixed type, and the acid rain in some areas has shown that the pollution of the mixed air pollution will aggravate the pollution of coal dust, which resulting in the total loss of social economy will be much higher than the original estimate. As the same as flue gas desulfurization, in the prevention and control of atmospheric pollution, Flue gas denitration also plays a very important role[1].

There are three kinds of control methods of NOX in China, such as pre combustion control, combustion control and post combustion control[2]. Pre combustion control focused on less practical application due to its high costs, and the denitration efficiency of combustion control technology is not high, so it can not effectively control the NOX emission. Therefore, the newly built coal-fired boilers in our country are basically controlled by the dual means of combustion control and combustion control, Selective catalytic reduction (SCR) denitration unit. Because of the high removal rate of NOX and the simple operation, the selective catalytic reduction (SCR) method[3] is a widely used technology of flue gas denitrification at home and abroad.

\section{SCR Denitration Process}

SCR denitrification system is divided into ammonia storage area (ammonia station) and denitrification zone (reactor) according to the area and function of the equipment[4]. The denitrification process of coal fired power plant is shown in Fig. 1. The denitrification process is a reduction reaction process, which uses ammonia as a reducing agent to decompose the nitrogen oxides in the flue gas into harmless nitrogen and water. The main purpose of the denitrification system is to ensure that the NOx concentration in the flue gas can be ensured by adding a reducing agent. 
Ammonia is mixed with 20 times the volume of air, and then mixed with $320 \sim 420^{\circ} \mathrm{Cof}$ flue gas, through the catalyst denitration[5]. NO, which is difficult to dissolve in water, accounts for more than 95\% of NOx, As long as the NO concentration of the SCR outlet is controlled, the emission can reach the standard. In order to meet the required $\mathrm{NO}$ removal rate, the amount of $\mathrm{NH}_{3}$ is needed to compensate for the nonuniformity of the mixture. After escaping, ammonia reacts with $\mathrm{SO}_{3}$ to form $\mathrm{NH}_{4} \mathrm{HSO}_{4}$, which is a viscous residue at $150 \sim 200^{\circ} \mathrm{C}$, and is deposited on the cold end of the air preheater, which can cause blockage and corrosion, and reduce the service life of the equipment. Therefore spraying ammonia control not only to ensure that the SCR concentration of NOx exports is not exceeded, but also to control the escape rate of ammonia is not exceeded.

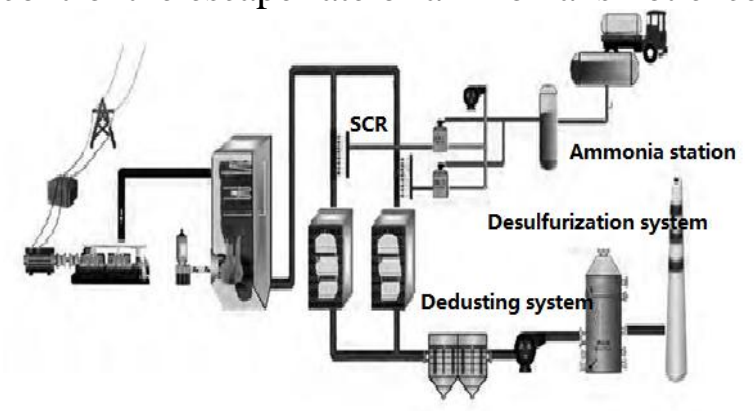

Figure 1. Denitration system of coal fired power plant

\section{Research on Control Strategy of SCR Denitration Based on Advanced Control Technology}

At present, the domestic SCR denitration closed-loop control strategy is usually designed as a fixed molar ratio control mode. The control method is based on the denitration efficiency and the ability of using the catalyst. In this control system, the system was used to remove NOx from flue gas according to the fixed ammonia nitrogen molar ratio. This control method is a set of adjustable single loop control system, the control circuit is simple and easy to debug and set, which is the advantage of this control method. However, this control system only takes into account the efficiency of denitration, and does not consider the change of the concentration of NOx, when the inlet NOx concentration is relatively low, it is easy to make the system over nitrogen and increase the operating costs.

In view of the above problems, this paper puts forward the advanced control technology of SCR denitration control in modern thermal power unit based on neural network learning technology and adaptive control technology, optimizing the control of ammonia flow rate and outlet NOx concentration of SCR. On the basis of taking full account of the denitration efficiency and the ability of denitration of the catalyst, the excessive nitrogen removal caused by the fixed molar ratio control is avoided, and the outlet NOx concentration can be controlled within a reasonable range. And control the ammonia escape rate close to SCR minimum amount of inherent, the air preheater cold end to produce ammonium hydrogen sulfate at least, minimize air preheater resistance increases, thereby reducing the consumption of electricity and maintenance plant, improve power generation efficiency.

General Scheme of SCR Denitration Control System. Through the SCR denitration control system operating environment, assessment requirements, the mathematical model of the controlled characteristics of accurate grasp, proposing an optimal control scheme based on neural network learning technology, adaptive control technology and optimal control scheme for SCR denitration control in thermal power plant, and the principle of the system is shown in Fig. 2.The intelligent feedforward technology was used to compensate the disturbance factors of the denitration control system, and the NOX concentration fluctuation was eliminated from the source. At the same time, the competitive neural network learning algorithm is used to correct the characteristic parameters of the dynamic compensation, and the he whole system is always in the state of online learning, and the control performance is approaching to the optimal goal[6].

Disposal of Measurement Data of Denitration System. As a result of the general use of condensate extraction flue gas analysis method, so the output value of the instrument has been dry 
standard state concentration, without conversion. The concentration of atmospheric pollutants as defined in the standard refers to the value of the dry flue gas in the standard state".

When the NOx concentration was measured on the front and back of the SCR reactor, the NO concentration can be measured by the on-line continuous monitoring system (CEMS)[4], Or the concentration of $\mathrm{NO}+\mathrm{NO}_{2}$. In the denitrification process, $\mathrm{NO}$ accounted for most of the NOx, the former can be measured, if it is emissions testing, it requires the measurement of total nitrogen, that is $\mathrm{NO}+\mathrm{NO} 2$. In order to facilitate the comparison with the monitoring data of environmental protection, the concentration of $\mathrm{NOx}$ is calculated by using the dry standard state $\mathrm{NO}_{2}$ in our country. Since the emission index of atmospheric pollutants is converted by the standard oxygen content, the concentration of oxygen in the dry standard state should be adjusted in the process of denitrification. Most of the nitrogen oxides after flue gas denitrification are discharged from the chimney, and only a small portion loss in the existing air preheater, dust collector, desulfurization process loss. Besides, in order to control the emission concentration, the SCR process should be unified with the environmental protection standard NOx.

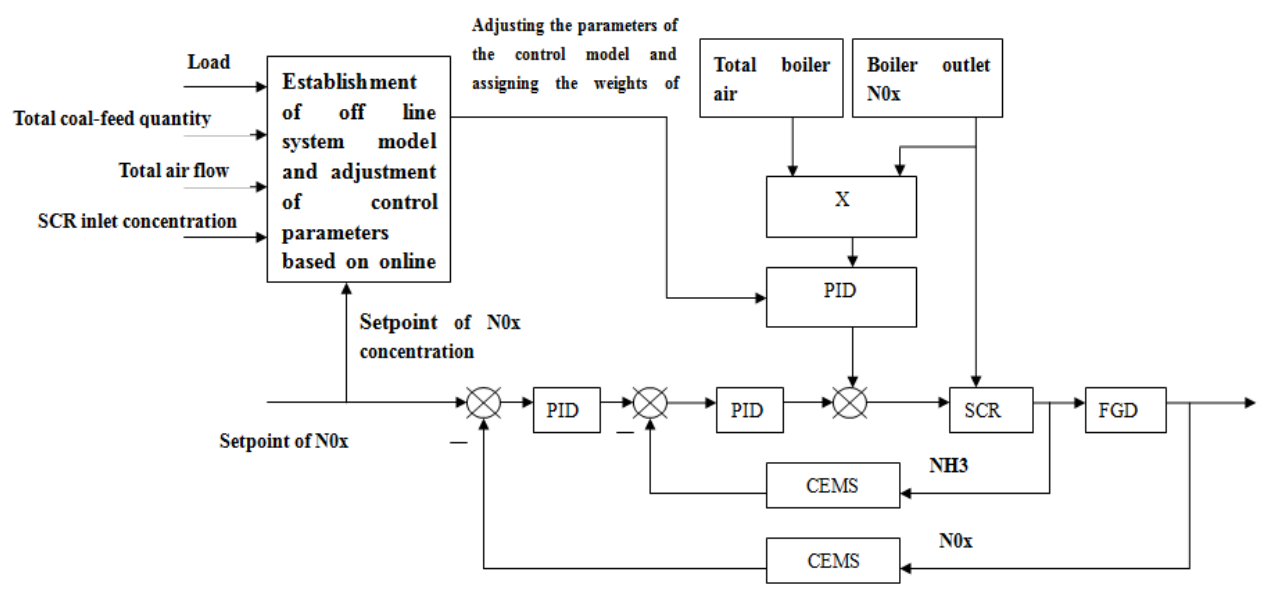

Figure 2. Optimized control scheme of SCR denitration system

Design of Parameter Optimization Module. The RBF neural network model of SCR denitration process[7] is established by using neural network technology to deal with the problem of nonlinear and time varying, the network structure is shown in Fig. 3.The intelligent feedforward technology was used to compensate the disturbance factors of the denitration control system, and the NOX concentration fluctuation was eliminated from the source. At the same time, the competitive neural network learning algorithm is used to correct the characteristic parameters of the dynamic compensation, and the he whole system is always in the state of online learning, and the control performance is approaching to the optimal goal. The SCR control technology and intelligent PID algorithm were used to optimize the control of ammonia flow rate and nitrogen oxide concentration[8].

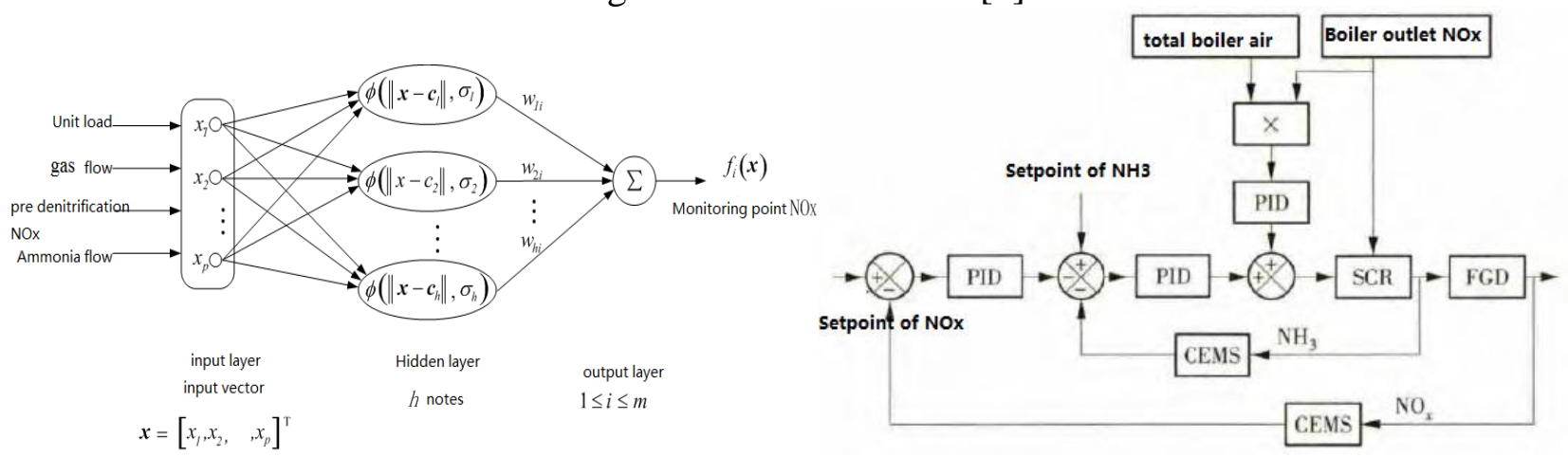

Figure 3. RBF network structure of SCR process Figure 4. SCR denitrification system block diagram

Design of Special Control Mode to Adapt To the Whole Working Condition. When the unit is stable, it can maintain the normal operation of denitration system by manual mode. However, when the 
working conditions change, the NOx concentration changes in a short period of time, the operator is difficult to control the excessive concentration of emissions or ammonia escape rate exceeded[9]. Therefore, a special control method is designed as a supplement to the normal control with Conditional switching implementation. The principle of the system is shown in Fig .4.

When the SCR inlet NOx concentration meter fails or is regularly maintained, the feedforward control function can be removed. When the SCR export NOx concentration monitoring instrument is faulty or regularly maintained, it can be switched to the closed loop control of ammonia escape rate. When the ammonia escape rate detection instrtument is not stable, only the large delay of the NOx is used in the closed loop control.

\section{Research on SCR Simulation System Based on Advanced Control Strategy}

In order to get rid of the limitations of the research work, it is necessary to set up a simulation experiment system, It is necessary to set up the simulation experiment system of denitrification process in laboratory. In order to make the research method and technology change to the industrial application as soon as possible, the simulation experiment system is built in a semi physical and semi virtual way[10]. The object of the denitration process is simulated by the model, and the control system, including the PLC control system, the control algorithm, the monitoring system, and so on is consistent with the industrial site. The structure of the whole system is shown in Fig.5.The algorithm studied in this platform can be verified in time, and it is easy to transform into industrial application.

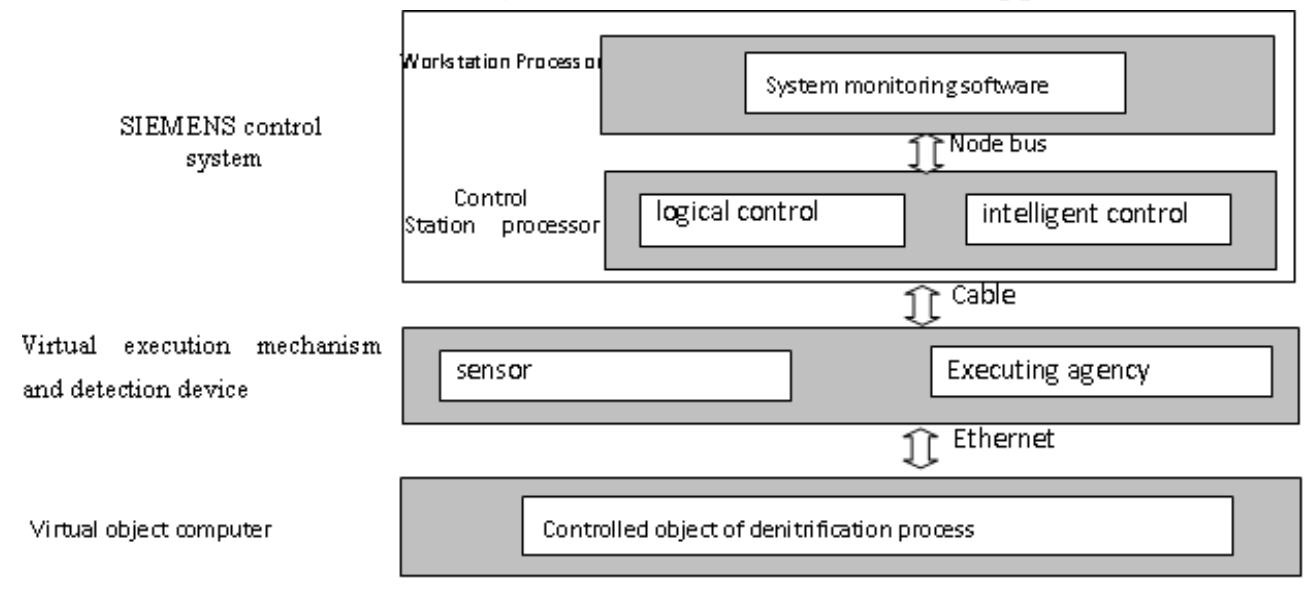

Figure 5. Simulation experiment platform

\section{Conclusions}

In this study, the optimal control method of denitration system can be used to control the NOx concentration of the chimney inlet in a reasonable range under the condition of stable load, fast variable load and start stop system, Moreover, it can achieve a significant economic benefit by ensuring a smaller ammonia escape rate. If we apply the advanced control technology to the similar industry, we can not only stabilize the production process, optimize the operation of the equipment, but also achieve the purpose of energy saving and emission reduction.

\section{Acknowledgements}

This work was supported in part by Liaoning Provincial Department of Education research project "Study on Optimal Control Strategy of SCR Denitration System" under Grant No. L2015367.

\section{References}

[1] S.J. Wan:Heilongjiang Environmental Journal, Vol. 38 (2014) No.2, p.1. 
[2] J. Bian,Y.G. Zhou and W.P. Liu: Resources Economization \& Environment, (2012) No.1, p.61.

[3] Nguyen T.D.B. ,Lim Y.I. and Eom W.H. :Computers \& Chemical Engineering, Vol. 34 (2010) No.10, p.1580.

[4] X.Y. Ni: Huadian Technology, Vol. 37 (2015) No.2, p.65.

[5] Z. Kang,F.N.Meng and X. Yang: Liaoning Chemical Industry, Vol. 44 (2015) No.2, p.158.

[6] Z.Y. Zheng,D.Huang: Jiangxi Electric Power, Vol. 170 (2014) No.5, p.75.

[7] J.K. Liu:Advanced PID control and MATLAB simulation ( Electronics Industry Press, Chinese 2003).

[8] A.M.Liu,G.B.Xu and Y.X.Yang: North China Electric Power, (2013) No.2, p.32.

[9] L. Wang,H.J. Li and L.P. Chen:Power Safety Technology, Vol. 17 (2015) No.1, p.44.

[10] H.Y.Zhai,J.P.Zhao and X.Q.Di: Computer Education, (2015) No.17, p.6. 